\title{
Research on the Development of Bilingual Broadcasting and Hosting under the Background of Globalization
}

\author{
Wei Deng \\ School of Humanities and Journalism \\ Xiamen University Tan Kah Kee College \\ Xiamen, China
}

\begin{abstract}
Globalization is increasingly developed. Economy, policy and culture have joined in the process of globalization, and the media sector is no exception. Globalization and internationalization have become the general trend. The new and diversified communication form is essential in order to keep up with the pace of development and to better join in the communication in this era. Bilingual broadcasting and hosting emerges and receives more and more attention during the international communication.
\end{abstract}

Keywords — bilingual; host; globalization; value

\section{INTRODUCTION}

Various kinds of languages emerge, develop, extinct and integrate in the development process of human society, thus today's structure is formed. English is widely used at present, and the American English and Australian English are derived; Chinese is also increasingly becoming the language in the ascendant attracting attention from the world; some other languages are declining day by day, and even disappear. However, the communication among various countries and nations is increasingly frequent and intimate. The cross utilization and mutual translation of two languages or more than two languages appear to be diversified both in daily communication and in broadcast and television programs, presenting a very wonderful and colorful form.

\section{CURRENT SitUATION OF BILINGUAL BROADCASTING AND HOSTING DEVELOPMENT}

Bilingual broadcasting and hosting refers to that the broadcaster (host), editor and journalist of radio station, television station, network and other audio-visual media institution to put the program together using the two normal languages alternatively (mainly English and Chinese), to conduct the cross-cultural communication activities with audible language.

\section{A. Normalization of the Two Languages}

To use two languages in the same program, the standards of both languages shall be followed. In addition, expression using two languages alternatively is not to mingle two languages arbitrarily. To pursue normalization of the two languages, we must start from three aspects, namely pronunciation, grammar and pragmatics, to put the program together using the two normal languages.

\section{B. Cross-cultural Communication}

Bilingual program is the platform for cross-cultural communication. The elements of the program are different, so the existence of difference in language and culture is inevitable. Facing different communication partner, bilingual program aims to overcome the obstacle of cross-cultural communication and build the bridge for cross-cultural communication.

The most important characteristic of globalization is that human has entered into an era of global communication, making us in a 24-hour interconnection and extremely active world. Under such background, audio - visual field is breaking away from the symbolic space scope of single national culture. In this colorful audio - visual world, people are experiencing the collision and integration of different culture. At this time, the diversified Chinese television program is moving towards a new field quietly. A new program form --- bilingual program emerges in the audio - visual world of China's audiences subtly. Chen Weihong, the bilingual host of "Two Sessions Viewed by Foreigners" of the two sessions' special program in 2007, made online dialogue with international observer in English in the studio, and offered comment in Chinese, making the amount of information of this program increased significantly. Beijing started to intensify the construction of medial bilingualism since 2011. It also develops foreign language broadcast and television program based on the existing frequency, channel and column, adds bilingual contents in the report, cooperates with foreign language education experts and foreign language training organization to record foreign language teaching program, providing services for citizens to learn foreign languages and understand foreign culture. In the report of two sessions of 2018, various media establish platform for media bilingual development utilizing network and mobile phone, giving play to the role of new media.

Bilingual broadcasting and hosting is the subject of competition in bilingual programs on radio and television. In the intense competition in media globalization, on the one 
hand, media is in urgent need of bilingual broadcasting host, and China's media is badly in need of cultivating their own bilingual broadcasting and hosting talents; on the other hand, in the western discourse system of global communication, we must express our viewpoints and establish our own media image through the two languages.

The Chinese broadcasting and hosting has undergone years of research and development, and there are many excellent theories and outstanding works. So far, the theoretical article and works specially studying the bilingual broadcasting and hosting art are quite few. The plentiful achievements of Chinese broadcasting and hosting art practice and theory is the foundation of its theory and the source of reference.

The level of China's bilingual broadcasting and hosting is unbalanced with many practice misunderstandings and unsatisfactory broadcasting effect. More and more people have mastered or need to master a second language no matter the Chinese audiences or foreign audiences. Bilingual broadcasting and hosting art carries multiple missions of information spreading, cultural communication and language communication, with wider development perspective.

The current situation and development of bilingual broadcasting and hosting is in urgent need of rational thinking, and the theoretical research must catch up with the pace.

\section{INFLUENCE OF HOST-ORIENTED SYSTEM}

With the development of modern science \& technology and economy, the competition among various media is intense, which will bring positive or negative influence to this society. As the spokesperson of media, the host not only represents the image of his/her own and the media, and sometimes the host even represents the mouthpiece of the Party and the stage. Their words, action, values and thought often guide the masses' emotion and the orientation of social public opinion. Therefore, the broadcaster and host should be restrict selfdiscipline and self-control, be responsible for every word they speak before the camera and microphone, to guide the public opinion correctly.

In the spread of television, the mass communication media, host is not only the starting point of communication activities, but also one of the centers of communication activities. Host is the supervisor of media communication, the embodiment of editing director's creation intention and the terminal of program completion, so he/she shall assume the responsibility for supervision of media information.

\section{VAlue of Bilingual Broadcasting AND Hosting} ART

\section{A. "Fever of Chinese Language" Promotes the Influence of Chinese Language Culture}

More and more China-invested enterprises go abroad with the continuous promotion of "The Belt and Road" construction to invest and build factories along this belt and road, which is the major opportunity for Chinese internalization. There are more and more demands in the international society to learn
Chinese. According to the statistics, the number of people who learn and use Chinese in the world has exceeded 100 million.

The role of Chinese in international economic trade and cultural exchange is outstanding, with its cultural value and practical value being enhanced constantly. Various countries in the world are generally optimistic about China's development prospects. Once a national language is established as a world language, the international position of this language's country and nation can be consolidated and improved. From this perspective, the globalization of Chinese will mean its culture's influence in the world. In other words, it is to spread the vitality and influence of Chinese language via the universality of English. Taking advantage of bilingual audio language mass communication to accelerate Chinese to move towards the world and letting the world hear Chinese is conducive to the enhancement of Chinese language's influence worldwide.

\section{B. The Explosion of Information Reveals More of the Host's Significance and Value}

The broadcaster and host's ability of processing information using "single language" is no longer able to manage today's news. Nowadays, media connection within the shortest time is of no problem in terms of technology. "Connection interview" has become the report form generally adopted by various media, but "single language" connection interview is increasingly not competent to the diversified information collection and comment; at the first scene of international outburst incident, our voice position is revealed totally. Bilingual broadcasting ability can help our host to appear on camera at the scene quickly, to take initiative to make comment, occupy the speech space of news report, and spread different voices from various places of the world in a timely manner. The enhancement of bilingual broadcasting ability can help us to occupy advantage quickly, improve the reputation of China's news media, strengthen China's competitiveness against western news media in international news report, thus to become the powerful means of China to introduce China's current development situation and elaborate Chinese government's standpoint and viewpoint to domestic and foreign audiences truthfully.

\section{Promote International Communication of China's Values}

Bilingual broadcasting and hosting art is the most reasonable cultural framework and discourse system of audio language communication. On the one hand, as the commonly used language, English can provide the world with relax and convenient mode to understand Chinese culture; on the other hand, Chinese is the most primitive expression of Chinese cultural characteristics, which can reflect China's mainstream culture truthfully to the largest extent. The world excellent culture will go beyond the national boundary of its national culture through bilingual audio language communication and spread across the world quickly. Bilingual broadcasting and hosting will make contribution to the trans-culture communication of China's values. 


\section{NeCESSITY FOR Host to Have BILINGUAL ABILITY}

Prior to the outburst of Iraq war, Chen Xiaonan, the host of Phoenix television, went deep to the war area to report. She talked with the Iraq guide using English smartly to learn about condition of the local public for a while, and then she held microphone dictating the news event using outstanding Chinese facing the audiences. She was confident and resolute, just like a rose in the battlefield, leaving profound impression to the audiences as one of the few Chinese hosts who have such excellent bilingual ability.

We often see the hosts preside over programs wearing headset of simultaneous interpretation. Some people think that the broadcasting host can also complete the communication relying on translation or simultaneous interpretation if do not have bilingual ability. But in the program of interview, which is in the situation of "talking" every minute, and the expression ability of host is established on the basis of complete "listening" ability. If the host is unable to speak both of the two languages and can only communicate with the foreign guests and audiences through translation, then problems will emerge. When talking to the foreign guests, we should understand that different mood and gesture of the foreign guests will have different meanings. For example, the short and powerful words of the speaker may convey that he/she is bored and anger; if the voice is dragged very long companying with controlled high pitch, that may be full of threat; especially, foreign guests have many expressions and gestures while talking, which are of abundant meanings...the tiny body language difference cannot be conveyed in place by the simultaneous interpretation; even though they are conveyed in place, the lagging speed of translation may not convey it in time. The non-simultaneous and even inconsistent lagging voice of interpreter with the guest's body language happens occasionally. Only the broadcasting host is of the bilingual ability, can he/she understands and manages the changes in the scene actively.

The authority of media lies in that the provider of information source and information must be the party involved or the witness, or the final determiner of the accident. In this sense, Chinese media shall always grasp the original information source in terms of news report. Especially in the live news reporting of international outburst event, no matter in the studio or the news spot, news anchor or host's bilingual ability can relieve the dilemma of insufficient language tools when reporting news in urgency situations.

\section{CONCLUSION}

With the opening of Chinese media and the expansion of conversation partner, we shall advertise China's image using news, strive to report it the earliest, to improve the authority of China's news report, thus the "hidden" bilingual ability of audio language spreader appears to be very necessary; facing the party involved in or witness of the news in different languages and different cultural background, on-line dialogue and in-time comment, the "obvious" bilingual ability is a new signal as whether the media in new era is of international competitiveness.
In addition, host shall also pay attention to the cultivation of his/her own local awareness, to convey local information and culture to foreign audiences, and introduce foreign culture to local audiences; take initiative to give play to his/her own unique role for the construction of local characteristics in "globalization" media environment, so as to facilitate international cultural communication and promote the image of China.

\section{REFERENCES}

[1] Zhao Lin. Art of Bilingual Broadcasting and Hosting. Beijing: Communication University of China Press. 2007.1-202. 赵琳.【双语播 音主持艺术】.北京: 中国传媒大学出版社.2007.1-202.

[2] Zeng Zhihua. Research on the Influence of Chinese Television Program Host's Culture. Beijing: Peking University Press. 2008.1-199. 曾志华 【中国电视节目主持人文化影响力研究】.北京: 北京大学出版 社.2008.1-199.

[3] Wen Fang. Bilingual Broadcasting and Hosting. Wuhan: Huazhong University of Science \& Technology Press. 2011.1-211. 文芳.【双语播 音主持】.武汉：华中科技大学出版社.2011.1-211.

[4] Lin Haichun. Art of English Program Host. Beijing: Communication University of China Press. 2009.1-283. 林海春.【英语节目主持艺 术】.北京: 中国传媒大学出版社.2009.1-283.

[5] Zhang Song. On Language Harmony Art. Beijing: Communication University of China Press. 2009.1-220. 张颂.【语言和谐艺术论】.北 京: 中国传媒大学出版社.2009.1-220 